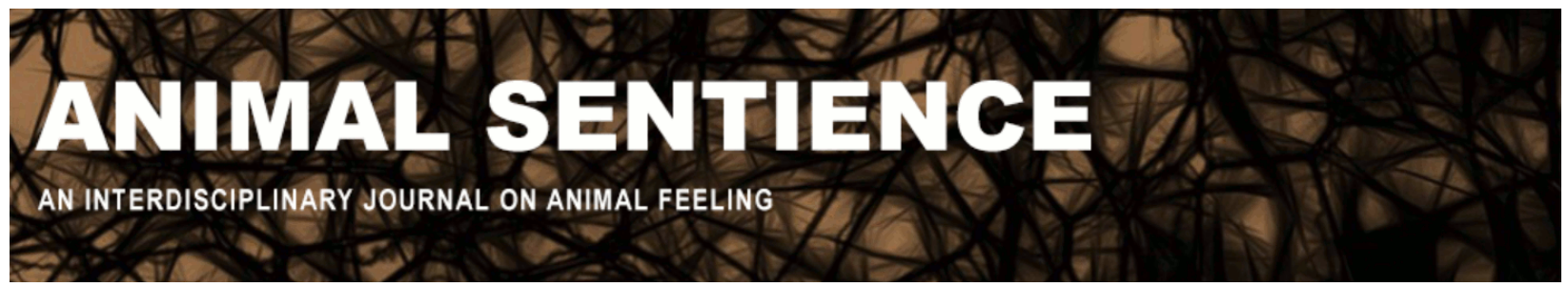

Taschereau-Dumouchel, Vincent; Grimaldi, Piercesare; and Lau, Hakwan (2017) Can unconscious brain processes indicate sentience?. Animal Sentience 13(15) DOI: $10.51291 / 2377-7478.1277$

Date of submission: 2017-12-15

Date of acceptance: 2017-12-17 (c)

This article has appeared in the journal Animal Sentience, a peer-reviewed journal on animal cognition and feeling. It has been made open access, free for all, by WellBeing International and deposited in the WBI Studies Repository. For more information, please contact

wbisr-info@wellbeingintl.org.

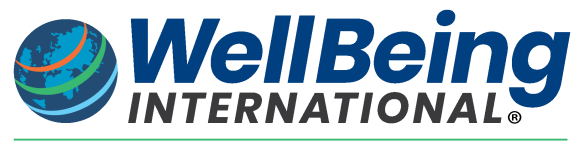

SOLUTIONS FOR PEOPLE, ANIMALS AND ENVIRONMENT 


\title{
Can unconscious brain processes indicate sentience?
}

\author{
Commentary on Woodruff on Fish Feel
}

\author{
Vincent Taschereau-Dumouchel ${ }^{1,2}$ \\ Piercesare Grimaldi ${ }^{3,4}$ \\ Hakwan Lau ${ }^{1,2,5,6}$ \\ ${ }^{1}$ Psychology, UCLA \\ ${ }^{2}$ ATR Computational Neuroscience Laboratories, Kyoto, Japan \\ ${ }^{3}$ Psychiatry and Behavioral Sciences and Neurobiology, UCLA \\ ${ }^{4}$ Semel Institute for Neuroscience, UCLA \\ ${ }^{5}$ Brain Research Institute, UCLA \\ ${ }^{6}$ Psychology, University of Hong Kong
}

\begin{abstract}
We disagree with Woodruff that we have good neurobiological reasons to think fishes are sentient, because mechanisms for consciousness are controversial even in humans. To the extent that there are consensuses in that literature, they do not support Woodruff's claims.
\end{abstract}

Vincent Taschereau-Dumouchel, postdoctoral scholar at UCLA, is developing a new unconscious NeuralReinforcement method to treat anxiety disorders in realtime functional magnetic resonance imaging.

Piercesare Grimaldi, Staff Research Associate at UCLA, is studying the neural bases of perceptual decision making and the metacognitive awareness associated with decisions.

Hakwan Lau, Associate Professor of psychology at UCLA and University of Hong Kong, is studying why some perceptual and cognitive processes in the brain are conscious while others are not. qualia.psych.ucla.edu/

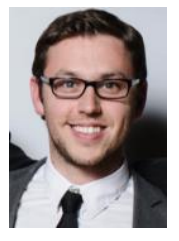

The nervous systems of fishes and mammals are different in many ways. Consequently, some have doubted whether fishes are sentient, that is, whether they have conscious experiences. Woodruff (2017) argues convincingly that fishes and mammals are actually more similar than previously thought. However, the neurobiological mechanisms for consciousness are controversial even in humans. Just the fact that the fish nervous system has some features 'thought' by some to be potentially relevant for consciousness in mammals should not give us much confidence in drawing strong conclusions about conscious experiences in fishes. There are also mechanisms thought to be important for consciousness, which may be missing in fishes. 
Let's start by addressing some processes thought to be conscious in humans and not discussed in Woodruff's target article on fishes. First, working memory has been closely linked to consciousness in mammals. This cognitive process involves the maintenance and manipulation of information in the short term (Baddeley, 2003), and some experiments have indicated that working memory cannot operate unconsciously. Though this view has been challenged recently (Soto, Mäntylä, \& Silvanto, 2011; Trübutschek et al., 2017), this still remains a mechanism potentially central to consciousness.

Second, consciousness has been associated with the global availability of information to different subsystems in the brain (Dehaene \& Naccache, 2001; Dehaene, Lau, \& Kouider, 2017). Neural counterparts of this are observed in neurophysiological recordings comparing conscious and unconscious visual presentations (Dehaene \& Naccache, 2001; Dehaene et al., 2017). Do fishes have such a mechanism for global broadcasting conscious information to various subparts of their brains?

Third, the capacity to reflect on one's own cognitive processes (i.e., self-monitoring or metacognition) has also been suggested to require the awareness of the processes being monitored (Dehaene et al., 2017; Lau \& Rosenthal, 2011). This has been studied using reports of self-confidence (Maniscalco \& Lau, 2012) and other behavioral evaluations of one's own knowledge (Dehaene et al., 2017; Lau \& Rosenthal, 2011). Do fishes have such a capacity too?

These key processes are discussed at length in the human literature and are absent from Woodruff's paper. Experimental tasks have been successfully adapted to non-human animals to study working memory (Carruthers, 2013; Dudchenko, 2004), global availability (Panagiotaropoulos, Deco, Kapoor, \& Logothetis, 2012) and metacognition (Odegaard et al., 2017; Smith, 2009). In principle, these could also be studied in fishes, but as of now we do not know whether their brains can support these key computations.

Woodruff does cover some mechanisms in fishes that are complex and sophisticated, but the consensus in the human literature is that such mechanisms can operate without awareness too. For example, isomorphic organization may well be present in early sensory cortices in both humans and fishes, but it is well known that neurons in these structures can be active unconsciously in humans (Dehaene et al., 2017). Selective attention, sometimes considered the gateway to consciousness, has been shown to be possible to operate unconsciously in human blindsight (Kentridge, Heywood, \& Weiskrantz, 1999). The same argument applies to the gamma band oscillations associated with selective attention and sensory binding. Gamma oscillations are not thought to reflect conscious processes exclusively (Merker, 2013).

Woodruff also presents results suggesting that the dorsomedial (DM) pallium fulfills a function analogous to the human amygdala in defensive behaviors; he writes that "the DM is part of a distributed neural system that generates the feeling of fear." This is in contradiction with human studies indicating that the amygdala is not necessary for the feeling of fear (Anderson \& Phelps, 2002; Feinstein et al., 2013). It is also in contradiction with findings indicating that subliminal threats can activate the amygdala without generating a conscious experience of fear (Lapate et al., 2016; LeDoux \& Pine, 2016; Mineka \& Ohman, 2002; Whalen et al., 2004). It is possible that processes occurring unconsciously in humans are also conducted without awareness in fishes, hence they cannot constitute proof of fish sentience

Other processes discussed by Woodruff remain debated in the human literature. Such is the case with the role of reentrant connections or recurrent processing. Some have suggested 
that consciousness requires higher sensory areas to interact with low-level sensory regions via feedback connections (Lamme, 2006), but this view remains contested (Lau \& Rosenthal, 2011).

Another debated process is trace conditioning. The presence of trace conditioning in fishes represents an interesting finding, as some results indicate that it might require consciousness in humans (Clark \& Squire, 1998; Knight, Nguyen, \& Bandettini, 2006). However, this remains controversial, as some recent works also show that the brain reactivity associated with trace conditioning can be observed with unconscious stimuli (Balderston, Schultz, Baillet, \& Helmstetter, 2014) and even in comatose patients (Juan et al., 2016).

In summary, it is still too early to determine "what it feels like to be a fish." Fishes are not included in the Cambridge Declaration on Consciousness (Low et al., 2012), but that list itself is by no means definitive. For scientists to gain credibility on such important matters, we need to distinguish between known empirical facts and mere opinion. For the relevant empirical investigation, the human brain is a good initial point - from which we are really just starting.

\section{References}

Anderson, A. K., \& Phelps, E. A. (2002). Is the human amygdala critical for the subjective experience of emotion? Evidence of intact dispositional affect in patients with amygdala lesions. Journal of Cognitive Neuroscience, 14(5), 709-720.

Baddeley, A. (2003). Working memory: Looking back and looking forward. Nature Reviews. Neuroscience, 4(10), 829-839.

Balderston, N. L., Schultz, D. H., Baillet, S., \& Helmstetter, F. J. (2014). Rapid amygdala responses during trace fear conditioning without awareness. PloS One, 9(5), e96803.

Carruthers, P. (2013). Evolution of working memory. Proceedings of the National Academy of Sciences, 110(Supplement 2), 10371-10378.

Clark, R. E., \& Squire, L. R. (1998). Classical conditioning and brain systems: The role of awareness. Science, 280(5360), 77-81.

Dehaene, S., \& Naccache, L. (2001). Towards a cognitive neuroscience of consciousness: Basic evidence and a workspace framework. Cognition, 79(1-2), 1-37.

Dehaene, S., Lau, H., \& Kouider, S. (2017). What is consciousness, and could machines have it? Science, 358(6362), 486-492.

Dudchenko, P. A. (2004). An overview of the tasks used to test working memory in rodents. Neuroscience and Biobehavioral Reviews, 28(7), 699-709.

Feinstein, J. S., Buzza, C., Hurlemann, R., Follmer, R. L., Dahdaleh, N. S., Coryell, W. H., Welsh, M. J., Tranel, D., \& Wemmie, J. A. (2013). Fear and panic in humans with bilateral amygdala damage. Nature Neuroscience, 16(3), 270-272.

Juan, E., Nguepnjo Nguissi, N. A., Tzovara, A., Viceic, D., Rusca, M., Oddo, M., Rossetti, A. O., \& De Lucia, M. (2016). Evidence of trace conditioning in comatose patients revealed by the reactivation of EEG responses to alerting sounds. Neurolmage, 141, 530-541.

Kentridge, R. W., Heywood, C. A., \& Weiskrantz, L. (1999). Attention without awareness in blindsight. Proceedings of the Royal Society B: Biological Sciences, 266(1430), 1805-1811.

Knight, D. C., Nguyen, H. T., \& Bandettini, P. A. (2006). The role of awareness in delay and trace fear conditioning in humans. Cognitive, Affective \& Behavioral Neuroscience, 6(2), 157-162. 
Lamme, V. A. F. (2006). Towards a true neural stance on consciousness. Trends in Cognitive Sciences, 10(11), 494-501.

Lapate, R. C., Rokers, B., Tromp, D. P. M., Orfali, N. S., Oler, J. A., Doran, S. T., Adluru, N., Alexander, A. L., \& Davidson, R. J. (2016). Awareness of emotional stimuli determines the behavioral consequences of amygdala activation and amygdala-prefrontal connectivity. Scientific Reports, 6, 25826.

Lau, H., \& Rosenthal, D. (2011). Empirical support for higher-order theories of conscious awareness. Trends in Cognitive Sciences, 15(8), 365-373.

LeDoux, J. E., \& Pine, D. S. (2016). Using neuroscience to help understand fear and anxiety: A two-system framework. The American Journal of Psychiatry, 173(11), 1083-1093.

Low, P., Panksepp, J., Reiss, D., Edelman, D., Van Swinderen, B., \& Koch, C. (2012). The Cambridge Declaration on Consciousness. Presented at the Francis Crick Memorial Conference on Consciousness in Human and non-Human Animals, University of Cambridge, UK.

Maniscalco, B., \& Lau, H. (2012). A signal detection theoretic approach for estimating metacognitive sensitivity from confidence ratings. Consciousness and Cognition, 21(1), 422430.

Merker, B. (2013). Cortical gamma oscillations: The functional key is activation, not cognition. Neuroscience and Biobehavioral Reviews, 37(3), 401-417.

Mineka, S., \& Ohman, A. (2002). Phobias and preparedness: The selective, automatic, and encapsulated nature of fear. Biological Psychiatry, 52(10), 927-937.

Odegaard, B., Grimaldi, P., Cho, S. H., Peters, M. A. K., Lau, H., \& Basso, M. A. (2017). Superior colliculus neuronal ensemble activity signals optimal rather than subjective confidence. https://doi.org/10.1101/157123

Panagiotaropoulos, T. I., Deco, G., Kapoor, V., \& Logothetis, N. K. (2012). Neuronal discharges and gamma oscillations explicitly reflect visual consciousness in the lateral prefrontal cortex. Neuron, 74(5), 924-935.

Smith, J. D. (2009). The study of animal metacognition. Trends in Cognitive Sciences, 13(9), 389396.

Soto, D., Mäntylä, T., \& Silvanto, J. (2011). Working memory without consciousness. Current Biology: $C B, 21(22), \mathrm{R} 912-\mathrm{R} 913$.

Trübutschek, D., Marti, S., Ojeda, A., King, J.-R., Mi, Y., Tsodyks, M., \& Dehaene, S. (2017). A theory of working memory without consciousness or sustained activity. elife, 6.

Whalen, P. J., Kagan, J., Cook, R. G., Davis, F. C., Kim, H., Polis, S., McLaren, D. G., Somerville, L. H., McLean, A. A., Maxwell, J. S., \& Johnstone, T. (2004). Human amygdala responsivity to masked fearful eye whites. Science, 306(5704), 2061.

Woodruff, M. L. (2017). Consciousness in teleosts: There is something it feels like to be a fish. Animal Sentience 13(1). 